\title{
EDUCAÇÃO FÍSICA E A LINGUAGEM DO HIP HOP: UM DIÁLOGO POSSÍVEL NA ESCOLA
}

\author{
Ingrid Patrícia Barbosa de Oliveira, Instituto Federal de Educação, Ciência e \\ Tecnologia do Rio Grande do Norte, Rio Grande do Norte - Brasil \\ Alison Pereira Batista, Instituto Federal de Educação, Ciência e Tecnologia do Rio \\ Grande do Norte, Rio Grande do Norte - Brasil \\ Rosie Marie Nascimento de Medeiros, Universidade Federal do Rio Grande do Norte, \\ Rio Grande do Norte - Brasil
}

\section{RESUMO}

Este artigo objetiva relatar uma possibilidade de ação pedagógica com a linguagem do Hip-hop como conteúdo de dança nas aulas de Educação Física com a organização do ensino pautada na perspectiva histórico-crítica da Educação Física. Esta intervenção foi realizada na Escola Municipal Prof. Otto de Brito Guerra, localizada no bairro do Planalto, instituída na rede pública de ensino da cidade do Natal. Os personagens deste estudo são 32 alunos de uma turma do $7^{\circ}$ ano do Ensino Fundamental, com faixa etária entre 11 e 13 anos de idade e que tinha em seu repertório gestual um interesse pelo universo do Hip-hop. O que determinou a abordagem deste tema foi o estudo da realidade realizado com a turma, no sentido de identificar as características presentes no cotidiano dos alunos. O ponto de partida, então foi saber quais as apropriações que os alunos faziam do Hip-hop no sentido de desmistificar certos preconceitos e ampliar o conhecimento sobre esta manifestação dançante. A experiência da dança Break-Dance, a apreciação de vídeos e o diálogo com o grupo de Hip-hop Conjunção promoveu aos alunos a compreensão dos papéis sociais existente nos diversos contextos em que o Hiphop se manifesta.

Palavras-Chaves: Educação Física escolar; Conteúdo dança; Break; Hip-hop.

\section{PHYSICAL EDUCATION AND LANGUAGE OF HIP HOP: A DIALOGUE POSSIBLE AT SCHOOL}

\begin{abstract}
This paper aims to report a pedagogical action possibility with the Hip-hop language of dance as content in physical education classes with the teaching organization guided by the historical-critical perspective of Physical Education. This intervention was conducted at the Municipal School Pr. Otto Guerra de Brito, located in the Plateau neighborhood, established in the public schools in Natal-RN. This study characters are 32 students of a $7^{\text {th }}$ grade class of elementary school, aged between 11 and 13 years old and who had in their gestural repertoire an interest in the world of Hip-hop. The approach to this topic was determined by a reality's study performed with the group, in order to identify the characteristics present in the student's daily life. The starting point was to know which appropriations of Hip-hop were made by the students with the purpose of demystify certain prejudices and broaden the students' knowledge of this dance demonstration. The Break-Dance experience, video appreciation and dialogue
\end{abstract}


with the Hip-hop group Conjunction, promoted students understanding of existing social roles in the various contexts in which Hip-hop is manifested.

Key-Words: Physical Education; Content dance; Break; Hip-hop.

\section{EDUCACIÓN FÍSICA Y EL IDIOMA DE HIP HOP: UN DIÁLOGO POSIBLE EN LA ESCUELA}

\section{RESUMEN}

Este documento tiene por objeto informar una posibilidad de acción pedagógica con el lenguaje de la danza hip- hop como contenido en las clases de educación física con la organización de enseñanza guiada por la perspectiva histórico-crítica de la Educación Física. Esta intervención se realizó en el Pr Escuela Municipal. Otto Guerra de Brito, situado en el barrio de Plateau, establecida en las escuelas públicas de la ciudad de Natal. Los personajes de este estudio son 32 estudiantes en una clase de séptimo grado de la escuela primaria, de edades comprendidas entre 11 y 13 años de edad y que tenía en su repertorio gestual un interés en el mundo del Hip-hop. ¿Qué determina el enfoque a este tema fue el estudio de la realidad realizada con el grupo con el fin de identificar las características presentes en la vida cotidiana de los estudiantes . El punto de partida y luego había que saber que los estudiantes eran créditos de Hip-hop con el fin de desmitificar ciertos prejuicios y ampliar el conocimiento de esta demostración de baile de los estudiantes. Experiencia Danza Break-Dance, vídeos de apreciación y el diálogo con el grupo de Hip-hop Conjunción promovido los estudiantes la comprensión de los roles sociales que existen en los diversos contextos en los que se manifiesta Hip-hop.

Palabras-Clave: Educación Física; Danza contenido; Break: Hip-hop. 


\section{HIP-HOP NAS QUEBRADAS!}

Este relato de experiência traz como tema central a cultura Hip-hop nas aulas de Educação Física. Consideramos que a cultura Hip-hop é utilizada como meio de inclusão social e cultural, pois jovens de diversas idades e níveis sociais têm se apropriado desta cultura no seu cotidiano com roupas, dança, arte, música e estilo. Ultimamente este universo está em evidência em nossa sociedade, vemos reportagens de televisão, filmes, novelas e até mesmo empresas têm usado este contexto como tema de seus comerciais para anunciar os seus produtos. No entanto, o movimento do Hip-hop vai além destes conceitos estabelecidos pela mídia internacional.

Este artigo objetiva relatar uma possibilidade de ação pedagógica com a linguagem do Hip-hop como conteúdo de dança nas aulas de Educação Física com a organização do ensino pautada na perspectiva histórico-crítica da Educação Física. Esta intervenção foi realizada na Escola Municipal Prof. Otto de Brito Guerra, localizada no bairro do Planalto, instituída na rede pública de ensino da cidade do Natal. Os personagens deste estudo são 32 alunos de uma turma do $7^{\circ}$ ano do Ensino Fundamental, com faixa etária entre 11 e 13 anos de idade e que tinha em seu repertório gestual um interesse pelo universo do Hip-hop. Os objetivos traçados para esta experiência constituem de analisar criticamente e esteticamente os estilos musicais do contexto do Hip-hop; experimentar os ritmos e os estilos de Break, bem como aprender a perceber as diferenças (pessoais, culturais, políticos) nas danças criadas e apreciadas; Conhecer o funcionamento das posses no movimento Hip-hop, em uma comunidade de periferia. Esta experiência se passa no enfoque de quatro momentos (oito aulas) numa organização de aulas para quatro semanas: o primeiro momento descreve o diálogo estabelecido com os alunos que tinha o interesse de conhecer quais as apropriações que os alunos faziam da cultura do Hip-hop; o segundo momento descreve as aulas em que os alunos tiveram a oportunidade de ampliar seu conhecimento sobre a cultura do Hip-hop através da apreciação auditiva do Rap e através da apreciação de vídeos; no terceiro momento relatam-se as aulas em que vivenciaram a "dança de rua", chamada de Break Dance através de desafios com a estratégia da improvisação. O Break Dance é uma expressão intitulada pela mídia no ano de 1984 para unificar os estilos de danças do B.boyin'g, Popin'g e Lockin'g, porém a expressão: Street Dance ou dança de rua se popularizou muito mais forte. Neste momento contemplaram os três estilos do Break e realizaram 
também o Free Style, oportunizando, portanto a construção de seus próprios repertórios de movimento. E por último relata-se o "encontro" que tiveram com grupo Assunção de Hip-Hoppers do Bairro Guarapes, que se organizam em forma de posses. Este momento permitiu que os alunos apreciassem mais de perto o trabalho que desenvolviam com projetos na comunidade.

A mola propulsora para a efetivação deste trabalho surge como um desafio, pois após o estudo das atividades diagnósticas quando na insinuação de sua possibilidade pedagógica, surgem discursos preconceituosos e de intolerância por parte de alguns discentes e da própria direção da escola. Presenciamos discursos de alguns colegas professores de Educação Física declarando a sua aversão ou dificuldade em trabalhar com o conteúdo de Dança no seu ensino de Educação Física, sobretudo a dança do Hiphop, julgando ser uma dança "difícil e complicada" para abordar com os seus alunos. No nosso ponto de vista, o termo "difícil" revelou o pensamento reducionista de que é necessário saber dançar para ensinar. Então percebemos que muitos se negam a essa experiência e "selecionam" os conteúdos a serem ensinados através de sua afinidade e habilidade, impossibilitando aos alunos outras linguagens que possam ser mais significantes. Já o termo "complicada", consideramos que enfocou o preconceito com a dança do Hip-hop por enxergá-la como fábrica de alunos com comportamentos "inaceitáveis", com o uso de roupas estranhas, gestos e gírias não "apropriadas" para o ambiente escolar. Além disso, tiveram discursos que declararam que o Hip-hop era incentivador do uso de drogas e da prática de crimes. Este enfoque preconceituoso foi declarado também por alguns professores da própria escola em que foi feita a intervenção, inclusive pela direção da escola que manifestou receio e preocupação com a repercussão das aulas de Hip-hop na Educação Física, alertando "cuidado" para os alunos não ficarem "cheios de malandragem".

Esse fato foi inquietante e impulsionador, pois acreditamos que negar essa manifestação que se faz presente no cotidiano dos alunos porque pode causar problemas, apresenta-se ao nosso olhar como uma alternativa não coerente. Por que não articular essa manifestação à Educação Física ou a outras disciplinas também nos momentos em que forem oportunos e significativos? A perspectiva histórico-crítica imbuída nos estudos de Elenor Kunz ${ }^{1}$ e no Soares et al. $^{2}$ foi usada como referência conceitual para a organização deste ensino, portanto, a orientação indicada é que o conhecimento deve Conexões: revista da Faculdade de Educação Física da UNICAMP, Campinas, v. 12, n. 2, p. 166-189, abr./jun. 2014. ISSN: 1983-9030 
partir da realidade dos alunos, necessitando de um fazer compreendido, ou seja, um fazer de natureza vivencial, refletido, contextualizado, buscando a apropriação experiencial e crítica das formas de movimentar-se. Uma perspectiva de ensino em que os alunos tenham acesso ao conhecimento de forma que lhes permita agir sobre esse mundo em que vive. Para tratar o conhecimento da cultura de movimento na escola, Melo apud Araújo, ${ }^{3}$ relata que se faz necessário que a Educação Física reconheça o acervo de movimentos que o aluno traz para a escola, resultado de um diálogo corporal com o seu entorno cultural. Este procedimento é um desafio, pois indica uma forma diferente de organizar o ensino, de tratar o conhecimento. Segundo Kunz, ${ }^{1}$ é uma forma de criar possibilidades para um entendimento crítico da realidade por eles vivida.

O que determinou a abordagem deste tema na Educação Física foi o estudo da realidade, atividade diagnóstica, realizado no início do ano letivo com algumas turmas da escola, no sentido de identificar as características de movimento presentes no cotidiano dos alunos. Para Pernambuco, ${ }^{4: 25}$ “o estudo da realidade onde esta localizada a escola permitirá a descoberta de conteúdos pertinentes e significativos para o cotidiano dos alunos na perspectiva de que possam agir melhor neste contexto em que vivem". Tal procedimento indica uma nova forma de visualizar os conteúdos e os métodos. Destaca ainda que seja necessário se fazer uma revisão crítica, e também, adequá-los às vivências dos alunos e dos professores.

Tentando alcançar estas sugestões, diagnosticamos e percebemos que a cultura do Hip hop estava bem presente no cotidiano deles, pela expressividade no gosto da música do rap, os gestos nas oportunidades de dançar e se expressar, nas vestimentas e gírias que usavam etc. Neste sentido, ficou evidente a manifestação do Hip-hop como sendo bem expressiva dentre os estilos de músicas que gostavam de ouvir e dançar. Este fato foi o indicativo para desenvolver a linguagem do Hip-hop nas aulas de Educação Física, abordando principalmente o elemento da dança como expressão do movimento.

Sentimos então, a necessidade de saber quais eram as apropriações que os alunos da turma faziam do universo do Hip-hop. O ponto de partida, então foi saber quais as características do Hip-hop que eles consumiam ou vivenciavam. Tibúrcio e Porpino, ${ }^{5}$ por exemplo, destacam que muitos espaços e situações frequentados pelos alunos estão repletos de sentidos e gestualidades de várias manifestações, inclusive aquelas que Conexões: revista da Faculdade de Educação Física da UNICAMP, Campinas, v. 12, n. 2, p. 166-189, abr./jun. 2014. ISSN: $1983-9030$ 
fazem parte do discurso da mídia que geralmente priorizam algumas dessas referências em detrimento de outras, deturpando muitas vezes seus sentidos vivenciais. Nesta perspectiva é importante compreender a necessidade de conhecer a apropriação que os alunos fazem dessa cultura e quais os sentidos e significados que eles expressam para essa manifestação.

Neste sentido, solicitamos que os alunos trouxessem os vídeos ou as músicas que mais gostavam e a partir da apreciação destes na aula, foi descoberto que os alunos vivenciavam o Hip-hop em contextos diferentes, mas ainda não conseguiam enxergá-los em sua hibridez que se refere a um processo de tradução cultural, agonístico uma vez que não se completa, mas que permanece em sua indecidibilidade.

Muitos vídeos que trouxeram apresentavam clipes com um cenário de mansões milionárias, com os Hip-hoppers exibindo motos, carros luxuosos e muitas mulheres bem produzidas apresentando os corpos seminus. Um cenário de ostentação e supervalorização da beleza padronizada. Paradoxalmente a este cenário, os alunos trouxeram também os vídeos e músicas do grupo Racionais que retratam uma realidade diferente, apresentavam clips que emplacavam uma resistência à intolerância ao negro, as injustiças e ao preconceito ao pobre, denunciavam a opressão e desabafavam seus anseios e desejos. Pelos discursos estabelecidos em sala de aula, percebemos que eles gostavam mais de ouvir o rap americano com a configuração de ostentação, porém, sem o conhecimento, na maioria dos casos, do que as músicas revelam e/ ou significam. No segundo momento foram feitos alguns questionamentos para os alunos no sentido de conhecer melhor a manifestação do Hip-hop no seu cotidiano. Dividimos então os discursos sob duas perspectivas para destacar os sentidos dados a essa manifestação.

$\mathrm{Na}$ primeira destacamos um contexto de Hip-hop americano com discursos que fomentavam a discriminação dos alunos com o negro e o pobre, a supervalorização do dinheiro e dos corpos seminus das mulheres: "Hip-hop é coisa de nego e pobre, mas é legal!’(Aluno Negro)“... mas não é só de pobre não professora, tem uns negão com altos carros”. “... os melhores é das mulheres gostosas, tudo nos carrão também”! "É assim: As mulher gostosona tudo em cima dos cara ricão". “... eu acho que o Hip-hop dos americanos é mais organizado eles fala de violência e droga as vezes, mas a batida é mais legal e as mulheres são mais bonitas". Na segunda perspectiva percebemos nos Conexões: revista da Faculdade de Educação Física da UNICAMP, Campinas, v. 12, n. 2, p. 166-189, abr./jun. 2014. ISSN: $1983-9030$ 
discursos a compreensão de um Hip-hop que retrata a realidade da periferia, enfocando a presença da violência, das drogas e da luta contra o preconceito racial: “... mas o Racionais não é assim, eles fala da periferia deles, eles fala da realidade deles". "O Hiphop é pra pobre e nego que vive no mundo de violência"! "Eles fala de drogas e crimes, mas eles querem que as pessoas não descriminem". "... eu acho que nada disso é do bem, porque eles falam de usar drogas e fazer crimes". "mas eles querem que ninguém tenha preconceito com eles". Na terceira perspectiva destaco uma associação direta entre Hip-hop, música e dança, como se todos fossem a mesma coisa: "Hip-hop é um tipo de dança". "O Hip-hop é muito difícil de fazer, por isso eu não sei fazer". “...é um ritmo legal que movimenta todo o corpo, principalmente no chão”! “... é uma música muito legal que contagia o nosso coração"!

A partir das narrativas apresentadas pelos alunos e pelas imagens contextuais dos vídeos, podemos destacar que a apropriação de valores e significados do Hip-hop se faz de uma forma acrítica, não encontram nos modelos referências e vínculos com a crítica realidade que os cerca. Compreendo que muitos alunos ainda não conseguem ver o Hiphop para além dos carros luxuosos, jóias e erotização presente nas letras e clipes de rap norte-americano. Ou em outro ângulo, também não conseguem compreender o Hip-hop como um movimento social que tem por foco a consciência crítica e a busca de soluções para os problemas de sua localidade.

\section{CONVERSAS: HIP-HOP PRAZER EM CONHECER!}

O planejamento das aulas requisitou a pesquisa de referencias que pudessem esclarecer melhor o que é o Hip-hop. As contribuições vieram principalmente do autor Maurício Priess da $\operatorname{Costa}^{6}$ que tratou de abordar as manifestações dançantes de cada escola do Hip-hop (Old School e New School) e William de Góes Ribeiro ${ }^{7}$ que revelou os limites, potenciais e desafios ao desenvolvimento de um projeto com uma prática cultural específica, tal como o Hip-hop na escola, numa perspectiva multicultural crítica. Segundo Costa, ${ }^{6}$ a nossa sociedade capitalista descobriu no Hip-hop uma maneira de lucrar. Ele não é um estilo musical ou um estilo de dança. Também não pode ser considerado um estilo de vida ou uma moda, um jeito de se vestir como a mídia insiste em apresentá-lo. Destaca que é um movimento muito maior que tudo isso. O trecho do 
livro vermelho do Hip-Hop de Pimentel apud Costa ${ }^{6}$ ajuda a esclarecer o que é o Hiphop.

\begin{abstract}
Gente pobre, com empregos mal remunerados, baixa escolaridade, pele escura. Jovens pelas ruas, desocupados, abandonaram a escola por não verem o porquê de aprender sobre democracia e liberdade se vivem apanhando da polícia e sendo descriminados no mercado de trabalho. Ruas sujas e abandonadas, poucos espaços para o lazer. Alguns, revoltados ou acovardados, partem para a violência, o crime, o álcool, as drogas; muitos buscam na religião a esperança para suportar o dia-adia; outros ouvem músicas, dançam, desenham nas paredes. Por incrível que pareça, não é o Brasil. Falamos do guetos negros de Nova York nos anos 70, tempo e lugar onde nasceu o mais importante movimento negro e jovem de atualidade, o Hip-Hop. ${ }^{6: 82}$
\end{abstract}

É um movimento sócio cultural que visa à emancipação do negro e do pobre na sociedade, mediante a educação e a revolução. Porém, esse movimento vem sofrendo transformações a ponto de apresentar duas faces, duas culturas de Hip-Hop distintas: A Old school e a New school. Neste caso o Hip-Hop vira produto de consumo pela nossa sociedade capitalista (New School) e se contrapõe ao Hip-hop (Old School). No estudo feito por $\operatorname{Costa}^{6}$, estas escolas se manifestam de maneiras bem diferentes. A velha escola como pode ser chamada a Old School é formada pela organização de posses que tem o mesmo significado de gangue ou crew, que são os grupos que se reúnem para discutir ações, tomar decisões e treinar a prática do break, do grafite ou do rap para atender a compromissos de aperfeiçoamento e desenvolvimento de ações políticas e comunitárias. A New school se apropria do movimento despindo-o de seus valores e coloca como um novo produto de mercado, transformando em lucro. Costa ${ }^{6}$ desmistifica o Hip-Hop como bem de consumo da indústria cultural, colocando-o como movimento sócio-cultural, através de entrevistas feitas com os próprios praticantes.

Assim a Old school seria formada por qualquer membro da cultura HipHop que esteja ligado aos fatos históricos que construíram essa cultura, enquanto que a New School seria formada pelos dançarinos de academia, que não se interessam nem pelos fatos históricos nem pelos aspectos sociais promovidos pelo significado da cultura Hip-hop. São em sua maioria, fruto do que a indústria cultural impõe como padrão, na maneira de vestir, pensar e agir. ${ }^{6: 91}$

A partir dos estudos de Ribeiro, ${ }^{7}$ detectamos que o movimento do Hip-hop não se encontra hoje de forma "pura”. É um fenômeno que surgiu nos EUA, chegou a todo o mundo, inclusive no Brasil e adquiriu diversas apropriações. Lodi apud Ribeiro ${ }^{7}$ ressalta que a cultura do Hip-hop é uma cultura híbrida. Propagou-se por meio da indústria 
cultural, no qual a mesma tratou de influenciá-la. De acordo com Arce, ${ }^{8}$ o fenômeno é muito comum entre os importantes movimentos juvenis. Estes são vistos como forma potencial de lucratividade o que acaba, muitas vezes, por descaracterizar movimentos sociais, se aproximando do que Maffesoli ${ }^{9}$ denomina de Tribos Urbanas. De acordo com o autor, as tribos urbanas se constituíram na contemporaneidade como:

Uma forma de enfrentamento ao individualismo. Argumenta através de visões de mundo nas quais o Ex-tase (sair de si) estaria no prazer de estar junto, nos grupos e seus sentimentos de pertencimento. Nessa visão, não há intenções ou objetivos específicos para o interesse coletivo. Os grupos se reúnem simplesmente por sentir prazer em estar junto. Cabe ressaltar, que a mídia e a indústria cultural, se apropriam desse conceito que pode ter resultado, grosso modo, na criação de "diferenças". 9:127

Arce $^{8}$ afirma ser um fenômeno comum: aconteceu com o Punk, com o Funk, e com o Hip-hop. "A indústria cultural se apropria de maneira indébita (misappopriation) e devolve a sociedade um movimento 'enquadrado', agora como produto, da maneira que deseja vender". 8:182

A partir desse contexto que envolve o Hip-hop, acreditamos ser imprescindível ampliar o leque de conhecimentos dos alunos para além das informações divulgadas pela mídia, considerando os vários contextos, espaços físicos, características, praticantes e objetivos que permeiam a vivência das manifestações da cultura de movimento. Além disso, as aulas podem se constituir como espaços significativos para reatualização, ressignificação e criação de outras manifestações, como destaca Tibúrcio e Porpino. ${ }^{5}$ A partir deste esclarecimento foi perceptível que as abordagens coexistem e requerem um olhar crítico, na perspectiva de tornar as aulas um espaço para discutir, refletir, problematizar, apreciar e vivenciar de forma criativa a referida manifestação da cultura Hip-hop. Neste sentido, não faria sentido permitir que os alunos vivenciassem a dança do hip-hop sem um conhecimento mais aprofundado da cultura como um todo.

\section{VERBALIZANDO NA BATIDA DO RAP!}

Diante das apropriações confusas dos alunos sobre a linguagem do Hip hop, investimos na problematização do tema para que ampliassem o olhar para o universo a ser desbravado. Na primeira aula propriamente dita, foram distribuídos no meio do círculo de alunos alguns materiais que iriam servir de reflexões como os Dvd's e Cd's que 
estavam expostos no chão: Gabriel o pensador, Racionais, mix de Hip-hop (americano), Gog, apocalipse 16, b’boy-Redbul (americano), entre outros. Além disso, Desenhos feitos no papel (Esboço do Grafite) que foram trazidos por eles mesmos. Para incrementar as discussões, a aula girou em torno das seguintes questões: Quais daqueles grupos que estavam expostos vocês conhecem? Quem são as pessoas que compõem estes grupos? Em que contextos estão expressos e o que quer dizer estes grupos a partir das músicas e vídeos apresentados? Como se vestem e o que valorizam? A partir destas questões fizemos uma reflexão sobre os elementos e personagens do movimento do Hip-hop, a origem e a história dessa manifestação e suas abordagens expressas nos dias de hoje, retratando os sentidos e significados apropriados nas diversas possibilidades de atuação (rua - manifestação espontânea, palco-artístico-profissional-competitivo, na mídia nacional e americana, academias e na escola), desmistificando o Hip-hop como bem de consumo da indústria cultural, evidenciando como movimento sócio-cultural.

Além disso, os alunos foram descobrindo os elementos que compõem o Hip-hop e os personagens. Segundo Costa, ${ }^{6}$ são quatro elementos: a música (rap), a plástica (o grafite), a dança (o break) e também a consciência. Essa divisão se baseia na forma com que os elementos são transmitidos. Segundo Pimentel apud $\operatorname{Costa}^{6}$ há outra divisão para o Hip-hop, que se baseia nos praticantes dessas formas de transmissão, ou seja, quatro divisões: O Mc (mestre de cerimônias), que canta o rap e apresentam as atividades e shows, o DJ (Disc Jockey), responsável pela música que serve de base para o Mc ou os Rappers cantarem, o Grafiteiro, que expõe suas mensagens nas paredes e o $B$ ’boy, o dançarino.

A partir deste entendimento os alunos fizeram outras descobertas como, por exemplo: descobriram que existiam mais dois elementos que não conheciam, além da música e da dança, a arte do Grafite e a consciência. O esforço dos alunos de chamarem a dança de Break e a música de Rap se configura na compreensão de que o termo Hip-hop abarca uma amplitude maior englobando os quatro elementos e não somente um. Portanto passaram a dizer, por exemplo, "vamos dançar Break" ou "vamos ouvir um Rap", ao invés de "vamos dançar Hip-hop" ou "vamos cantar Hip-hop". Descobriram que os elementos e personagens nem sempre estão presentes em todos os contextos. "nos clipes de Hip-hop americano eu nunca vi a arte do grafite!"; "na academia eles não se preocupam muito com isso (grafite)".

Conexões: revista da Faculdade de Educação Física da UNICAMP, Campinas, v. 12, n. 2, p. 166-189, abr./jun. 2014. ISSN: $1983-9030$ 
Estas descobertas suscitaram um novo questionamento: se todos os elementos e personagens nem sempre estão inseridos num determinado contexto como na academia, por exemplo, podemos chamar essa manifestação de Hip-hop? Neste momento, confirma-se a compreensão dos alunos ao perceber que no contexto da academia existia somente o elemento da dança e sendo assim entenderam que neste contex to o elemento da dança se caracterizava no simples prazer de dançar, sem o interesse pelos aspectos sociais inerentes à cultura Hip-hop. Neste momento os alunos tiveram oportunidade de ouvir a explicação tratando do poder da indústria cultural em transformar as manifestações em produto de consumo. Ora, se tudo pode ser apropriado a fim de gerar bens de consumo, por que não o Hip-hop? Parece que a sociedade capitalista descobriu no Hip-hop uma maneira de lucrar.

Em seguida são questionados: vocês sabem que produtos são esses que a indústria cultural produz para nós consumirmos? Somente um aluno se manifestou e respondeu com uma indagação: “as roupas e as toucas que eles usam?”. Deu-se inicio a um processo de identificação de produtos que são "fabricados" pela indústria. Alguns deles estavam a nossa frente e foi motivo pra discussões, como os Dvd's e Cd's.

Dentre estes produtos ressaltamos a referência do DVD produzido pela indústria da Redbul (um produto de consumo) que atribui o mérito de campeão ao B’boy que se destacar melhor sob os olhos atenciosos dos jurados. Vale salientar que este produto é conhecido de muitos alunos da turma. Desde então refletimos a tendência que a nossa sociedade tem de transformar as manifestações em competição. Neste caso, apareceu a oportunidade de apreciar um pouco o vídeo em questão refletindo sobre os sentidos que existem quando a dança do break se configura numa competição. Os alunos não conseguiram enxergar de imediato estes sentidos, mas aos poucos foram reconhecendo, por exemplo, que existiam diferenças entre dançar num evento festivo e dançar numa competição: destacaram o medo do $\mathrm{B}$ ’boy em não errar, a preocupação com o julgamento do jurado, o sentimento de ter um adversário no palco e sentimento da torcida na plateia contra ou a favor a sua performance.

Estes momentos reflexivos que tivemos se articula com o que Kunz ${ }^{1}$ defende para o ensino baseados na concepção crítica, desenvolver as condições para que a imposição Conexões: revista da Faculdade de Educação Física da UNICAMP, Campinas, v. 12, n. 2, p. 166-189, abr./jun. 2014. ISSN: $1983-9030$ 
de uma "comunicação distorcida" possam ser superadas e encaminhadas no sentido de uma emancipação que corresponda à realidade.

O ensino da concepção crítico-emancipatória deve ser um ensino de libertação de falsas ilusões, de falsos interesses e desejos, criados e construídos nos alunos pela visão de mundo que apresentam a partir de "conhecimentos" colocados à disposição pelo contexto sociocultural onde vivem. . $^{1: 121}$

Desse momento, os alunos receberam várias cópias de músicas de Rap para ouvirem alguns trechos e em seguida se manifestarem através da linguagem diante de algumas questões. As encenações reveladas pelas músicas escolhidas permitiam que os alunos enxergassem vários contextos e significados que são inerentes a esta cultura do Hip-hop tão dinâmica. As músicas apreciadas foram "Razão para Viver" do happer GOG, "Estudo Errado" de Gabriel Pensador, "A Minha Oração" do grupo Apocalipse 16, Stillu.R.E de Joe Budden, um rapper americano e "Verdadeiro Hip-hop" do Mv Bill.

Usamos como estratégia para o diálogo na atividade a proposta das perguntas operacionalizadas que foram expressas assim: Quais são os personagens? Qual espaço de atuação? Qual é contexto social em que se passa a música? Quem são as pessoas envolvidas nesta música? O que eles representam? Qual é a mensagem da música? Qual é o objetivo do autor da música? O que revela pra nós a música americana? Qual das músicas se enquadra no Hip-hop da Velha Escola e da Nova escola?

Estas questões tiveram o objetivo de fazê-los ver o Hip-hop de uma maneira diferente, como por exemplo, enxergar além de mulheres, carrões e cordões de ouro dos clipes produzidos pela MTV, ou então, algo diferente do que mostram filmes americanos e propagandas de marcas famosas, como meninos de boné, calça larga, tênis e que falam "esquisito". Enxergar o que tem por trás das diversas apropriações que a indústria cultural faz do Hip-hop em prol de uma re-significação, com fins de torná-lo produto para o consumo. Ribeiro ${ }^{7}$ destaca, são construídas imaginárias "realidades" e uma pluralidade de discursos que desta forma, muitas vezes, criam-se preconceitos que não permitem uma aproximação entre o Hip-hop e educação formal.

Neste sentido, podemos destacar que os alunos tentaram classificar as músicas que ouviram diante das perguntas propostas, compreendendo os personagens, os espaços em 
que são enfocados, o contexto social e a mensagem que a música representa para os ouvintes. Fizeram também uma analogia de cada música com as características do Hiphop da Velha escola e Nova escola. Os personagens, os espaços de atuação e contexto social foram identificados com muita facilidade. Porém, a turma sentiu dificuldades para perceber a mensagem principal de cada música, necessitando de outras perguntas que ajudassem essa percepção.

Para a música "Razão para Viver" do happer GOG os alunos destacaram os personagens como sendo os jovens usuários de drogas que vivem na periferia, compreenderam que a mensagem da música é para as mães desses filhos drogados que sofrem com as atitudes perversas do mundo das drogas. O objetivo é fazê-las refletir sobre o dilema que os filhos passam e que possam ajudá-los exercendo o perdão e a oração. Para os alunos a música representa o quanto é sofrido este cenário, atribuindo um sentimento de aversão ao consumo de drogas. Estas discussões permitiram que os alunos se preocupassem mais em ouvir a música toda e perceber a mensagem que está contida, pois os alunos revelaram que às vezes ao ouvirem trechos das músicas julgavam logo como sendo de apologia as drogas e crimes. E na verdade a mensagem que estava contida na história da música clamava um desejo de sair do mundo das drogas e crimes para uma vida melhor!

A música "Estudo Errado" de Gabriel Pensador foi destacada pelos alunos em um contexto diferente da música anterior. A música se passa com o relato de um menino de classe média que não gosta de estudar: "a música de Gabriel o pensador fala para os filhinhos de papai, que ganham mesada". Os alunos sentiram muita dificuldade em extrair a mensagem da música que criticava a maneira que os alunos "aprendem": copiando, decorando, memorizando e a maneira que os professores "ensinam" desatualizados, desmotivados.

"A Minha Oração" do grupo Apocalipse 16 foi à música que alunos tiveram mais facilidade de classificá-la, pois de imediato um dos alunos discursou: "acho que a música do apocalipse se enquadra no contexto da periferia também, mas o desejo deles é falar principalmente de Deus, da oração e existe uma vontade de as pessoas mudarem pra melhor". Ao ouvir a música do rapper americano os alunos curtiram a batida rindo porque não compreendiam a letra da música. “... esse Rap americano é bom de ouvir a 
batida, o ritmo, mas como nós não sabemos inglês, não sabemos a sua mensagem e então não tem graça".

O "Verdadeiro Hip-hop" do Mv Bill fez com que os alunos enxergassem melhor o que é o Hip-hop da velha escola, aquele que mantém o foco na consciência crítica e na busca de soluções para os problemas de sua localidade. Diante das discussões estabelecidas os alunos passaram a denominar os contextos de "verdadeiro" ou "falso" Hip-hop. Mas será que podemos denominar assim? Estas denominações nos leva a pensar que os alunos compreenderam a existência de contextos que tendem a assumir características da New Shool ou da Old School, mas podemos destacar que estas características em determinados contextos podem coexistir.

A partir desse momento pode-se perceber que eles atribuíram significados para o Hiphop além daqueles que possuíam, trazendo uma maior visibilidade em torno da indústria de consumo e do preconceito e discriminação dos negros e pobres. Assim, pode-se dizer que esta aula aconteceu permitindo que os alunos vivenciassem a reflexão e a comunicação, pois a interação alunos-professor e professor-alunos não podem acontecer sem a participação da Linguagem. Os alunos nesta aula foram estimulados a falarem, expressarem suas histórias e opiniões verbalmente. Neste sentido, se configurou no desenvolvimento da competência comunicativa que exerce um papel decisivo para o desenvolvimento da competência educacional crítico-emancipatória. Segundo Kunz. ${ }^{1: 41}$

Saber se comunicar e entender a comunicação dos outros é um processo reflexivo e desencadeia iniciativas do pensamento crítico. Mas a competência comunicativa na Educação Física e Esportes não deve se concentrar apenas na linguagem dos movimentos que precisam acima de tudo, ser compreendidos pelos integrantes de um jogo ou atividades lúdicas, mas principalmente, a linguagem verbal deve ser desenvolvida.

A didática comunicativa como chama este autor, pretende libertar o aluno das condições que limitam o uso da razão crítica e com isto todo o seu agir social, cultural e esportivo. Houve uma preocupação em conseguir mudanças, problemáticas que permitisse a busca de soluções, embora saiba que ainda há que enxergar outras "encenações" que poderíamos permitir que nossos "alunos" enxergassem. 


\section{DESBRAVANDO OS LIMITES NO BREAK DANCE!}

"O medo de fazer o que não sabe é o que nos limita de mostrar a nossa capacidade." (Grupo SNJ).

Antes de iniciar esta aula com a temática do Break, foram feitos alguns preparativos para ilustrar e ajudar na dinâmica. Colocamos na parede um mural com a frase descrita acima e junto com ela colocamos várias expressões que caracterizavam a dança do Break: boyin'g, popin'g, lockin'g, top rock, up rock, foot work, freeze, boogaloo, Power movies, flair, parada de mão, moinho de vento, giro de cabeça, wave, fre style, new school, old school. Iniciamos a aula com esta frase porque os alunos estavam com grandes expectativas em vivenciar a dança do B’boy, o Break. Mesmo solicitando que não se preocupassem com essa aula, muitos deles já estavam dizendo que não sabiam e não iam fazer porque a dança era muito difícil de realizar. A referência que tinham da dança era a do vídeo produzido da Redbull o qual abordamos sobre ele anteriormente, uma competição de $B^{\prime}$ boys que tinham um desejo de ganhar e por isso apresentavam movimentos performáticos que requeriam dos $B$ boys uma grande habilidade. Talvez este referencial os fizesse se sentir incapazes de dançar o Break e a estratégia de iniciar refletindo a frase foi para que os alunos tomassem a iniciativa de se disponibilizar corporalmente para a vivência.

Essa preocupação em conquistar os alunos para ousarem a experimentar o Break não poderia ficar somente na reflexão da frase, pois a metodologia a ser usada deveria ser coerente para que os alunos vivenciassem criativamente a atividade proposta. Barreto ${ }^{10}$ em sua obra que fala sobre o ensino da dança na escola, por exemplo, chama atenção para que esse ensino seja planejado numa concepção de dança-educação. Um ensino que possibilite o aluno decidir, criticar, criar e expressar o que sente e pensa, no mundo em que vive. Para a autora o ensino da Dança pode exercer um importante papel no que se refere a ampliar as possibilidades e as formas de compreender, ampliar e se relacionar com o seu próprio imaginário, com o de outras pessoas e com este mundo em que vivemos. Esta preocupação se instala na busca de encontrar caminhos mais humanos de vivenciar as técnicas, a imaginação, a criação, a dança. Neste sentido não podemos escolher pedagogias que imobilizem os corpos com uma prática dos paradigmas mecanicistas, separando o ser que dança e quer conhecer de si, de sua autonomia e potencial criativo. ${ }^{10}$ Barreto $^{10}$ destaca ainda que devemos dar um sentido Conexões: revista da Faculdade de Educação Física da UNICAMP, Campinas, v. 12, n. 2, p. 166-189, abr./jun. 2014. ISSN: 1983-9030 
didático no ensino da dança contemplando os conteúdos de dança que se desdobra em técnicas de expressão de dança e a coreologia que é o estudo da análise de movimento iniciados por Laban. ${ }^{11}$

Além dessa perspectiva, queremos destacar também que consideramos a técnica de expressão sugerida pelos $\mathrm{PCNs}^{12}$ que inserem a dança na área da Educação Física, no bloco das atividades rítmicas e expressivas, que tem como característica as intenções de comunicação e de expressão, por meio de gestos e estímulos sonoros. Assim tomamos também as atividades rítmicas e expressivas como referencial para a vivência da dança do Hip-hop (o break), por considerar bem semelhante aos princípios sugeridos por Barreto. $^{10}$

A intenção neste primeiro momento da experiência era que os alunos se sentissem a vontade e se expressassem por meio de gestos e estímulos sonoros. Percebemos a necessidade de encaminhar, em aula, tarefas diferenciadas que permitissem que os alunos não realizassem exercícios prefixados, exigidos em função das técnicas, para a experiência com o break. Assim, buscou-se também os princípios da improvisação como conteúdo da dança na escola que segundo Fiamocini e Saraiva ${ }^{13}$ implica num processo que permite a todas as pessoas dançarem, ou movimentar-se expressivamente dentro das suas possibilidades individuais.

Para evitar o confronto do movimento com a formalidade da técnica, fizemos o que se chama de soltura com o intuito de possibilitar ações desteriotipadas e um processo criativo. Movimentavam-se de diversas formas pela sala de acordo com os ritmos de rap: várias formas de andar, de se arrastar, de rolar, etc. Os alunos iam vivendo os movimentos e ao mesmo tempo iam se relacionando com os colegas, criando vários jeitos de se cumprimentar. "Como vocês podem causar estranheza no seu colega? Criem outras formas de se cumprimentar!". "Como podem fazer isso com esse ritmo?" Esta experimentação livre e criativa objetivava que os alunos se relacionassem com o espaço e o tempo, e com outro no sentido de se ambientarem e sentissem livres para realizarem as próximas etapas. Esta estratégia didática para Fiamocini e Saraiva 13:102 “tem o intuito de transcender limites por meio da experimentação e consequentemente configurar nova aprendizagem de movimentos e gestos, por meio da representação". 
Depois disso os alunos passaram a vivenciar estruturas de movimentos que permitiram a expressão de diversas possibilidades de movimentos que estão inseridas nesta manifestação da dança do Break. Tomamos como base a leitura de Alves, ${ }^{14}$ que descreveu os movimentos da dança Break a partir dos estudos de Laban ${ }^{11}$ sobre a análise do movimento corporal, fundamentada em quatro fatores de movimento que são fator força/peso; espaço; tempo e fluência. Segundo ele, na cultura Hip-hop, o elemento dança é formado por três estilos originados em diferentes localidades no EUA: o break boyin'g, o popin'g, o lockin'g. Estes três estilos formam a base da dança break. Cada estilo possui uma nomenclatura diferente para qualificar seu dançarino: o break boy ( $B$ boy) é o dançarino da dança break boyin'g, o poper é o dançarino da dança popin'g e o locker é o dançarino da dança lockin'g. Estes estilos de dança no Hip-hop são envolvidos em uma única expressão: Break Dance.

Ao envolver num só termo, qualidades gestuais distintas de dançarinos distintos, a dança da cultura Hip-hop, ao seu modo, mostra que é uma manifestação da diversidade das ruas. Uma diversidade marcada por uma estética onde a característica principal é o hibridismo, ou seja, a colagem entre culturas diferentes..$^{14: 25}$

A partir deste referencial foi sendo lançando para a turma diversos desafios que contemplassem a vivencia dos três estilos do Break. Neste momento o aluno é guiado para um novo caminho, uma nova encenação como Kunz ${ }^{1}$ destaca em sua obra. Os alunos do $7^{\circ}$ ano tornaram-se descobridores e inventores do movimento. Começamos a estimulá-los através do estilo Popin'g uma maneira de dançar, na qual o dançarino vai dando trancos no corpo como se estivesse endurecendo todos os nervos e articulações. Este estilo surgiu na Califórnia que também é chamada de Boogie. Então foram desafiados por perguntas que implicavam em descobrir os gestos característicos deste estilo. As primeiras perguntas enfatizaram a realização de gestos de Robôs: "Como vocês podem se deslocar e se cumprimentar utilizando gestos de robôs?”; "O robô desliza sobre a superfície e como vocês realizam esse deslize do robô?"; "Como seu corpo se comporta ao realizar gestos de robôs?". Depois foram desafiados a brincarem com a onda que é como se fosse um impulso elétrico percorrendo o corpo de articulação em articulação e também os trancos que são os cortes bruscos nesta onda elétrica em curso. Foi perceptível a alegria em que os alunos brincavam com o seu corpo, descobrindo formas diferentes de expressar estes robôs eletrificados com as ondas. Segundo Alves, ${ }^{14}$ a performance do Popper é sempre surpreendente e se desenvolve como se ele usasse seu corpo como um brinquedo. 
Em seguida exploraram novos movimentos com o corpo a partir da problematização do estilo Lockin'g. Surgiu em Los Angelis por uma equipe chamada "The Lockers", que influenciou o estilo de vários artistas norte-americanos, entre eles, Madonna e Michel Jackson. Segundo o autor esta dança é caracterizada pela intensa ação dos braços, mãos e dedos que trabalham em vários planos num gesto de apontar. Neste caso os alunos foram desafiados a soltar os braços e as mãos de forma explosiva em todas as direções, depois experimentaram a realização de circunduções dos punhos antebraços e braços: "A partir deste ritmo como podemos movimentar nossas mãos e braços de uma forma explosiva, veloz"? "Como podemos colocar para dançar nossos braços, antebraços, mãos e dedos fazendo circunduções, giros"? "Quem consegue lembrar algum gesto que lembra o artista Michel Jackson ou a Madonna"? Neste momento os alunos riam muito uns dos outros, pois os gestos lhes causavam estranheza. $\mathrm{O}$ ato de acionar os braços em todas as direções com uma alta intensidade ou de imitar os gestos do cantor Michel Jackson permitiam a vivencia de movimentos não comuns no seu cotidiano.

O estilo Boyin'g que é a dança mais tradicional da cultura Hip-hop, surgiu junto com o nascimento do Hip-hop no bairro do Browx em nova Iorque (EUA). É caracterizado pelos movimentos de chão, como por exemplo: top rock, up rock, e foot work, freeze e boogaloo. Além destes o Power Movies: flair, moinho de vento, giro de cabeça. Ainda, através de perguntas desafiadoras foi contemplado este estilo, os alunos se sentiram desafiados a se equilibrar em diversos eixos de apoio descobrindo diversas possibilidades: "Quais as partes do corpo que podem ser os eixos"? "Como vocês podem se equilibrar em diferentes eixos"? "Quem consegue se equilibrar no eixo das mãos"? "Quais as posições que requerem mais força?”. As respostas foram expressas em forma de movimentos, os alunos descobriram vários eixos, apoiando o corpo em diversas posições: cabeça e mãos, uma mão só, as duas mãos, costas, mãos e face lateral do rosto, um pé, um pé e uma mão, pés e mãos, joelhos, calcanhares, face do rosto e joelho, etc...

Mas isso, não bastava depois eles passaram a dar respostas a um desafio maior, tentar fazer rotações sobre os eixos de equilíbrio, inversões: "Diante destes eixos que vocês conseguiram se equilibrar, será que conseguem fazer a rotação sobre os eixos?”. Os alunos tentaram realizar os giros sobre os eixos da cabeça, das mãos, de um pé só, das costas, etc. Alguns tiveram nas suas tentativas o prazer de conseguir a habilidade Conexões: revista da Faculdade de Educação Física da UNICAMP, Campinas, v. 12, n. 2, p. 166-189, abr./jun. 2014. ISSN: $1983-9030$ 
descoberta, outros se divertiam com as suas tentativas ora de sucesso ora de erro. Neste momento foram identificados alguns movimentos que alguns alunos conseguiram realizar e foi proposto para a turma tentar realizar também, como por exemplo, o Foot Work que o aluno Jason realizou. Para Alves, ${ }^{14}$ o Foot Work é um estilo em que os braços e as pernas sapateiam, na constate transferência do peso de um membro para outro. $\mathrm{O}$ dançarino está em quadrupedia e alterna constantemente sua posição em decúbito dorsal ou ventral, realizando giros para a troca de posição.

Os três momentos da aula que contemplaram a vivência criativa dos três estilos do Break foram encarados pelos alunos como desafios e estes se configuravam com características da dança. Em nenhum momento foi enfatizado para os alunos que estilos eram esses, e nem quais eram os nomes dos movimentos, pois foi preparado uma oportunidade para revelar estes estilos de uma forma que eles fossem descobrindo. Os alunos foram convidados a apreciarem o mural que estavam grafadas as palavras (boyin'g, popin'g, lockin'g, top rock, up rock, foot work, freeze, boogaloo, Power movies, flair, parada de mão, moinho de vento, giro de cabeça, wave, fre style, new school, old school) que iam desencadear as discussões: "Vocês conhecem algumas dessas expressões?" "Qual delas já ouviu falar?" "Porque algumas são expressões da língua inglesa?"

Os alunos identificaram as três palavras em português expressando o seu significado fazendo uma analogia com os movimentos da ginástica artística. As outras expressões não eram do seu conhecimento. A partir do que fizeram nas aulas foram descobrindo os estilos Boyn'g, Popin'g e Lockin'g, esclarecendo as diferenças a partir da análise de Alves $^{14}$ feita com o referencial de Laban. Cada expressão foi sendo explicada e comparada com as vivencias que tinham feito.

Depois dessa conversa, os alunos foram experimentar o Free Style. Este se caracteriza como um momento de criação em que cada participante entra na roda para apresentar a sua dança mediante a diversidade de gestos constituída no universo do Hip-hop, uma oportunidade de re-significar os gestos que vivenciaram nos desafios. Vão se constituindo novos desafios nas relações que estabelecem, um desafia o outro com repertórios motores próprios, um momento de participação livre e espontânea. Segundo 
Alves o Free Style é a arte performática do breaker. Na medida em que vai tomando para si os dados desta cultura ele vai criando o seu estilo, uma habilidade autoral.

A expressão Free Style é também conhecida como "charme" ou "ginga estilosa". Cada dançarino tem o seu charme, a sua ginga, o seu jeito de se expressar. Através do Free Style o breaker faz uso de um estilo para comunicar através deste repertório motor, algo de si mesmo. $\mathrm{O}$ atuante resignifica o gesto na medida em que vai experimentando este gestual, através de sua vivência corporal no Free style. . $^{1425}$

A performance motora dos alunos neste momento, ganha uma qualificação subjetiva. Observamos que nesta experiência os alunos além do repertório de estilos que constituem a Dança Break, fizeram o uso de outros recursos como, por exemplo, usaram as habilidades da capoeira e as gestualidades do funk. Estas linguagens se misturaram, pois usaram os repertórios já conhecidos, marcados em seus corpos, aliados com a criação de novas formas de se movimentar a partir das vivencias que tiveram anteriormente com o break, criando novos contextos e gestualidades. Segundo Fiamoncini e Saraiva ${ }^{13}$ o processo da improvisação em dança, acontece, também, uma transcendência de limites pela aprendizagem que se efetiva na transformação e construção de novas técnicas de movimento, na apreensão de conteúdos e na ressignificação do movimento.

Após a vivência os alunos expressaram no mural através de palavras ou frases as suas impressões, atribuindo um significado para as aulas que tiveram. Foi perceptível o envolvimento deles com as aulas, pois as frases expostas no mural demonstravam isso: "Eu gostei mais dos movimentos da dança do Boyin' $g$ ". "Nestas aulas eu aprendi várias coisas diferentes, gostei muito do estilo do robô, muito legal”! "O Hip-hop é dança, música e grafite, é uma obra de arte muito legal”! "O Hip hop é inspiração”! "O Hiphop é um meio de aprender a viver". "No Break você aprende a não desistir".

Algumas frases demonstraram a superação que alcançaram ao fazer a atividade que antes pensavam em desistir, pelo medo que tiveram de realizar a dança que julgaram ser difícil: "Nunca desista, sempre tente"! "Desistir jamais"! "Nunca desista de seu verdadeiro sonho! E não desamine o próximo!”; "Nunca desista do que não sabe, pois um dia você vai conseguir". "Acredite em você"! "Se cair se levante, se perder lute pelo o que". "Não deixar se abater pelas dificuldades vividas". "Não seja tímido, seja feliz", etc. Outras frases demonstraram a superação do preconceito que tinham com a 
manifestação do Hip-hop: "Se lutarmos juntos contra o preconceito do Hip-hop saberemos que não tem nada errado". "É preciso lutar contra o preconceito do Hiphop". "Aprenda a viver com o Hip-hop”! "O Hip-hop é movimento não só de violência, mas principalmente de paz”! "O Hip-hop é o desejo de ver a sua comunidade em paz”!

\section{ENCARARANDO A REALIDADE!}

Este momento foi uma oportunidade que os alunos tiveram de conhecer através de um encontro na sala de aula com alguns integrantes do Grupo de Hip-hop do Bairro do Guarapes na cidade do Natal, que se organizava através da posse de Hip-hop Lelo Melodia, localizado no Espaço Cultural Engenho de Sonhos que é comumente chamado de Conjunção. Os integrantes do grupo Conjunção, Edcelmo que é Dj e ex-B’boy e o Paulo Pedro chamado de PP que é produtor do grupo fizeram uma explanação a respeito do Hip-hop, relatando as suas experiências a partir da provocação das perguntas dos alunos. Deste modo falaram da origem do grupo até o seu amadurecimento enquanto posse, falaram dos projetos realizados na comunidade, do cotidiano vivenciado no bairro, do progresso que a comunidade teve a partir das suas intervenções, do sucesso do grupo, das viagens que fizeram a partir dos projetos, das reivindicações que fizeram no bairro através de políticas públicas, etc. Trouxeram vídeos produzidos por eles para os alunos apreciarem as suas mensagens e seu estilo de Rap, um Rap com ritmo de Reggae. Mistura que foi realizada para agradar aos integrantes que curtiam os dois estilos de músicas.

Os alunos curtiram muito as histórias dos rapazes, riram e fizeram muitas perguntas interessantes como, por exemplo: "Como começaram a participar do movimento do Hip-hop?" "Você já sofreu preconceito da sua própria família?" "Quem mais incentivou vocês a participarem desse movimento?" "Como é pra vocês conviver com os preconceitos das pessoas?" "Vocês ganham dinheiro com o Hip-hop?" "O que é a mídia para o Hip-hop, ajuda ou atrapalha?" "Quais os projetos que são realizados na posse em prol da comunidade?" "Alguém do grupo já foi ou é usuário de drogas?" "O que acham do grupo facção central que fazem apologia ao crime e ao uso de drogas?" "O que é o grupo conjunção para a comunidade do Guarapes?", etc. 
Depois desse bate e volta de perguntas e respostas o Dj Edcelmo fez uma demonstração de como utiliza a mesa de som, realizando alguns efeitos sonoros nas músicas. Alguns alunos tiveram a oportunidade de manusear e realizar alguns sons. Para finalizar a sua participação eles trouxeram para os alunos assistirem um poema declamado pelo Rapper Gog, intitulado como "os miseráveis" do autor chamado Vitor Hugo. Terminamos a aula com muitas palmas. Isto revela um pouco do encantamento dos alunos com a realidade da qual acabaram de conhecer.

\section{A PROCURA DA BATIDA PERFEITA}

Diante dos resultados apresentados, nas falas, questões, escritas no painel, expressão e participação dos alunos, o Hip-hop demonstrou ser um conteúdo possível na disciplina de Educação Física, pois através dele foi possível desenvolver os objetivos préestabelecidos. Como qualquer conteúdo curricular, se ordena para uma formação integral na medida em que trabalha com aspectos histórico-culturais, explora o movimento criativo, o conhecimento corporal, desafia o respeito às diferenças, alarga as limitações, conhece mais de seu contexto, entre outros. Acreditamos que os alunos tiveram oportunidades significativas para a construção de novos saberes, pois a inclusão deles nas atividades caracterizou não somente como reprodutores de gestos motores e teorias, mas se constituíram num ambiente de aprendizagem em que eles tiveram a oportunidade de fazer escolhas, partilhar e acolher informações, construir hipóteses, fazer questionamentos. Diante do exposto, destaco neste momento que esse trabalho se deu através de um grande desafio, pois as dificuldades enfrentadas se configuraram desde a discriminação e preconceitos de alguns professores e direção da escola com o tema, até a busca intensiva de materiais e pesquisas para elaboração das aulas. Neste sentido, fomos buscar atualizações para aperfeiçoar o ensino da Educação Física e especificamente da dança como conteúdo. Não temos como dimensionar o quanto alargaram o conhecimento, mas percebemos que a vivência com o tema proporcionou outros olhares e perspectivas. Percebemos que os alunos ampliaram a visão que tinham da manifestação do Hip-hop e que puderam ressignificar este contexto. Pensamos que este ensino não estanca o conteúdo, pois a partir disso poderão ser desencadeados outros conhecimentos, outras questões e problemáticas possam ser desdobradas. Além disso, destacamos que continuaremos a procura da batida perfeita no sentido de tentar acertar mais com o intuído de possibilitar novos olhares, novos gestos, novos sentimentos, 
novos discursos. Sentimos que esta intervenção poderia desencadear um projeto mais amplo com a participação de outros professores, no sentido de se fazer um trabalho interdisciplinar, acreditando que poderia ser ainda mais significativo e ampliado tendo em vista quebrar o preconceito imbuído neles também. Desejamos destacar também que usar os princípios da perspectiva histórico-crítica na organização de aulas de Educação Física requer sempre novas revisões e novos desdobramentos. Fica então aberto a novas significações que aqui não foram considerados, mas que possam complementar e ampliar esta vivência.

\section{REFERÊNCIAS}

${ }^{1}$ KUNZ, E. Transformação didático-pedagógica do esporte. Ijuí: Ed. da Unijuí, 1998.

${ }^{2}$ SOARES, C. L. et al. Metodologia do ensino de educação física. São Paulo: Cortez, 1992.

${ }^{3}$ ARAÚJO, A. Vivenciando a educação física escolar: um relato de experiência. In: NÓBREGA, T. P. (Org.). A Educação Física no ensino fundamental. Natal: Paidéia, 2006.

${ }^{4}$ PERNAMBUCO, M. M. Introdução. In: ; PAIVA, A. P. (Org.). Livro didático 1: pesquisando as expressões da linguagem corporal. Natal: Ed. da UFRN; PAIDÉIAMEC, 2005.

${ }^{5}$ TIBURCIO, L. K. O. M; PORPINO, K.O. Atividades rítmicas e expressivas na educação física. In NÓBREGA, T. P. (Org.). Livro didático 3: o ensino de Educação Física de $5^{\mathrm{a}}$ a $8^{\mathrm{a}}$ séries. Natal: Ed. da UFRN; PAIDÉIA-MEC, 2005.

${ }^{6}$ COSTA, M. P. A dança do movimento hip-hop e o movimento da dança hip-hop. In: FÓRUM DE PESQUISA CIENTÍFICA EM ARTES, 3., 2005, Curitiba. Anais... Curitiba: Escola de Música e Belas Artes do Paraná, 2005.

${ }^{7}$ RIBEIRO, W. G. “Nós estamos aqui!": o hip-hop e a construção de identidades em um espaço de produção de sentidos e leituras de mundo. 2008. 214 f. Dissertação (Mestrado em Educação) - Universidade Federal do Rio de Janeiro, Rio de Janeiro, 2008.

${ }^{8}$ ARCE, J. M. V. Vida de barro duro: cultura popular juvenil e grafite. Rio de Janeiro: Ed. da UFRJ, 1999. 182 p.

${ }^{9}$ MAFFESOLI, M. O tempo das tribos: o declínio do individualismo nas sociedades de massa. 4. ed. Rio de Janeiro: Forense Universitária, 2006. 297p. 
${ }^{10}$ BARRETO, D. Dança...: ensino, sentidos e possibilidades na escola. 3. ed. Campinas: Autores Associados, 2008.

${ }^{11}$ LABAN, R. Domínio do movimento. 3. ed. São Paulo: Summus, 1978.

${ }^{12}$ BRASIL. Ministério da Educação e Cultura. Parâmetros Curriculares Nacionais do $3^{\mathbf{0}}$ e $4^{0}$ ciclos: Educação Física. Brasília, 1998.

${ }^{13}$ FIAMOCINI, L.; SARAIVA, M. C. Dança na escola: a criação e a co-educação em pauta. In: KUNZ, E. (Org.). Didática da Educação Física 1. Ijuí: Ed. da Unijuí, 1998.

${ }^{14}$ ALVES, F. S. A dança do break: uma análise dos fatores componentes do esforço no duplo movimento de ver e sentir. Motriz, Rio Claro, v. 13, n. 1, p. 24-32, jan./mar. 2007. 